\title{
Globalization in Research
}

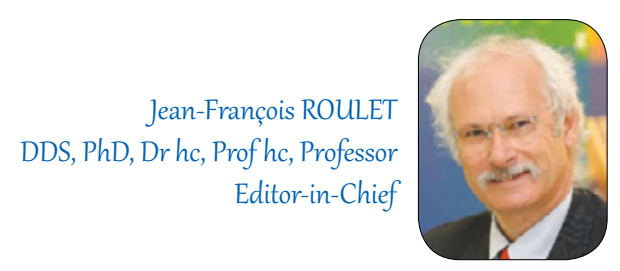

DearReaders,

The internet has completely changed our lifestyle. I shop using the internet, 1 book services through the internet, manage my banking transactions through the internet etc. When 1 have a question, 1 "google" it to find an answer, possibly with some bias 1 cannot control. The same happens in the way 1 conduct myself professionally. At any given time, the entire compilation of knowledge is accessible at the blink of an eye. Thus, 1 am much more informed than ever. But what happens in the case of research? In this area, 1 behave the same way as 1 did 40 years ago. If 1 have a question for which 1 do not get a satisfying answer by accessing the various databases, I go to my laboratory and try to find the answer by myself. At times, if needed, 1 have had to design special equipment, and with the collaboration of my coworkers, we have had to design new experiments to find the answers. If you think this through, this approach is not very efficient, because very often we have to "reinvent the wheel".

Today, this is about to change. Approximately a year ago, Prof. Werner Geurtsen from Germany and 1 decided to work together on a new project in order to put together a more efficient network for dental materials research. Based on this idea, we organized a mini-symposium on dental materials at the University of Florida in Gainesville. Researchers from Brazil, Germany, Switzerland and the USA were invited to discuss novel ways and ideas on how we could cooperate on an international basis. At the end of this meeting, we came up with the following model: provided that it were possible within the University's administrative rules, we would mutually be willing to accept visiting researchers from other Universities (as well as coworkers of researchers that are part of this group) at no cost, as long as the visiting researcher brought his/her own materials and paid for his/her own travel and living expenses. In otherwords, we would be opening our laboratories to our colleagues. As a first step, we started a master list of laboratory equipment available in each of the participant's laboratories. Meanwhile, the group has expanded and researchers from Canada and Romania joined.

This is a globalization in research effort for the benefit of everyone involved, because people can go to a particular institution and learn a method, discuss research projects and work together with researchers from other universities. I personally have had a long tradition with this type of experience and for many years have had visiting colleagues coming to my laboratory to work. It has always been a win-win situation for all participants. Furthermore, lifelong friendships have emerged from these experiences.

Dear colleagues, I would like to encourage you to contact me if you are interested in joining the group. We have named it the "International Center for Dental Biomaterials" and 1 believe it is a great opportunity to expand your research endeavors.

Sincerelyyours,

J-FRoulet

Editor-in-Chief

DOI: 10.25241/stomaeduj.2017.4(3).edit.2 